\title{
Stereotactic Radiotherapy and Androgen Deprivation Therapy for Localized Prostate Cancer: A Retrospective Mono-institutional Experience
}

\author{
ALESSANDRO MAGLI ${ }^{1}$, MARCO LORENZO BONÙ ${ }^{2}$, FABRIZIO TONETTO ${ }^{1}$, \\ EUGENIA MORETTI ${ }^{3}$, GIOACCHINO DE GIORGI ${ }^{4}$, LUIGI SPIAZZI ${ }^{5}$, MARCO TROVÒ ${ }^{1}$, \\ DAVIDE TOMASINI $^{2}$, STEFANO MARIA MAGRINI $^{2}$ and LUCA TRIGGIANI $^{2}$ \\ ${ }^{1}$ Department of Radiation Oncology, University Hospital of Udine, Udine, Italy; \\ ${ }^{2}$ Istituto del Radio O. Alberti, Department of Radiation Oncology, \\ University of Brescia and Spedali Civili Hospital, Brescia, Italy; \\ ${ }^{3}$ Department of Medical Physics, University Hospital of Udine, Udine, Italy; \\ ${ }^{4}$ Department of Urology, University Hospital of Udine, Udine, Italy; \\ ${ }^{5}$ Department of Medical Physics, University of Brescia and Spedali Civili Hospital, Brescia, Italy
}

\begin{abstract}
Background/Aim: Stereotactic radiotherapy $(S R T)$ is an effective treatment for localized prostate cancer. However, is it not clear whether the addition of androgen deprivation therapy (ADT) to SRT is beneficial. The aim of this study was to analyze the outcomes of a series of patients treated with SRT plus ADT for localized prostate cancer. Patients and Methods: Patients were treated with SRT with 42 Gy in 7 fractions with volumetric-modulated arc therapy plus Image Guided Radiotherapy (V-MAT IGRT) technique. $A D T$ was administered to patients with intermediate unfavorable- and high-risk disease. Study endpoints were biochemical disease-free survival (bDFS), overall survival $(O S)$, acute and late toxicity and patient-reported outcomes (PROs) using international prostate cancer symptoms scale (IPSS) and international index of erectile function (IIEF). Results: A total of 170 consecutive patients were identified, of which 49 (28.8\%) with low-risk, 15 (8.8\%) with favorable intermediate-risk 76 (44.7\%) with unfavorable intermediaterisk and $30(17.6 \%)$ with high-risk class. All patients of unfavorable intermediate- and high- risk groups were
\end{abstract}

This article is freely accessible online.

Correspondence to: Marco Lorenzo Bonù, Istituto del Radio O. Alberti, Department of Radiation Oncology, University of Brescia and Spedali Civili Hospital, Piazzale Spedali Civili 1, 25123, Brescia, Italy. Tel: +39 0303995272, Fax: +39 0303998565, e-mail: marco.bonu@unibs.it

Key Words: Prostate cancer, stereotactic radiotherapy, androgen deprivation therapy, unfavorable intermediate risk prostate cancer, high risk prostate cancer. administered LHRH analogue concurrently to SRT and for at least 6 months. Patients with unfavorable intermediateand high-risk presented a 5-year bDFS of $81.7 \%$ and $76.9 \%$, respectively. Conclusion: SRT consisting of 42 Gy in seven fractions with short-term ADT represents a safe and effective treatment for unfavorable intermediate and high risk prostate cancer. Our results support the need of high quality studies to test the efficacy of ADT combined with SRT for unfavorable intermediate- and high- risk localized prostate cancer.

The therapeutic landscape for localized prostate cancer is rapidly expanding. External beam radiotherapy (EBRT) is a non-invasive approach that offers the same curative outcome as radical prostatectomy (1). In recent years, the dramatic technological advancement, as well as evidence on the high radiation-fraction sensitivity of prostate cancer (2-5) led to the investigation of ultra-hypofractionated radiotherapy schedules.

Stereotactic radiotherapy (SRT) is a technique of using multiple beams to obtain high conformity to the target, high dose fall off, and high dose per fraction, hence to precisely irradiate the target volume, while minimizing the dose to the organs at risk. After initial encouraging results in early trials for localized prostate cancer, recent evidence established SRT as non-inferior to traditional EBRT (6-7). Early concerns about SRT-induced side effects have been overcome and high quality evidence proved that late toxicity is comparable to standard regimens (8). Taken together, these results render SRT an option for localized prostate cancer in low-, intermediate-, and selected high- risk patients (9). Careful patient selection as well as clinical and technical 
expertise are needed to safely perform a high quality treatment. When proposing standard EBRT, the standard of care for intermediate and high-risk patients is the combination with ADT (10). Despite the huge amount of data on SRT for localized prostate cancer, it is not clear wheter ADT could be of benefit also in such a new treatment scenario (11-14).

We therefore performed a retrospective analysis of a series of low-, intermediate- and high- risk prostate cancer patients treated at our institution, focusing on the evaluation of intermediate risk and high risk disease subclass and the possible effect of ADT on outcomes.

\section{Patients and Methods}

Patients. This is a retrospective monoinstitutional study, considering patients treated consecutively at our institution from 2013 to 2018. Inclusion criteria were age of 18-85 years, no prior ADT except 5alfa-reductase inhibitors, no other treatment before SRT for prostate cancer except for TURP performed for prostate-related symptoms, no regional or distant metastasis at computed tomography (CT) scan and bone scan performed maximum 2 months from the beginning of the treatment, IPSS $\leq 15$, prostate volume $<100 \mathrm{ml}$ and biopsyproven prostate acinar adenocarcinoma. Patients were classified according to the NCCN prostate cancer risk stratification as follows: low risk (LR) defined as ISUP grade group 1, T1-T2a, and PSA $<10$ $\mathrm{ng} / \mathrm{ml}$; intermediate risk (IR), defined by 3 features (ISUP group 2 3 , T2b-T2c, and PSA 10-20 ng/ml), were divided in favorable (only one intermediate risk feature and ISUP grade group 1-2 and $<50 \%$ biopsy core positive) and unfavorable (one or more of the following: two or three intermediate risk features and/or ISUP $>3$ and/or $>50 \%$ of biopsy core positive); high risk (HR) defined as ISUP $4-5$ or cT3a or PSA $>20 \mathrm{ng} / \mathrm{ml}$.

For unfavorable intermediate- and high- risk patients, ADT was permitted and consisted of at least a single dose of LHRH analogue $22.5 \mathrm{mg}$ or at least two doses of LHRH analogue 11.25 $\mathrm{mg}$. The maximum ADT duration allowed was 24-36 months. The local Ethics Committee approved the present study. Written informed consent to treatment and data collection was obtained from all patients.

Simulation, planning, and delivery. All patients were simulated in supine position, with empty rectum and bladder preparation in order to obtain at least $100 \mathrm{ml}$ of bladder volume. Specific immobilization System (Combifix, $\mathrm{CIVCO}^{\circledR}$, Coralville, IA, USA) was used for all patients, non contrast-enhanced CT scans were acquired $(2 \mathrm{~mm}$ slices) extending form lower trochanter to L2-3. All RT plans were generated by the same radiation oncologist using Eclipse Treatment planning system (Varian Medical Systems, Palo Alto, CA, USA). Diagnostic magnetic resonance imaging (MRI) was availed for contouring purpose. SRT schedule consisted of 42 Gy in 7 fractions on alternate days; dose prescription followed ICRU-83 recommendations, with the goal to deliver at least $95 \%$ of the prescription dose to $95 \%$ of PTV and dose at $2 \%$ of PTV less than $106 \%$ of prescription dose (15). Radiotherapy was delivered with volumetric-modulated arc therapy (V-MAT) Rapidarc ${ }^{\mathrm{TM}}$ technique using both conventional $6 \mathrm{MeV}$ beams (Clinac iX, Varian Medical Systems) and flattening-filter-free $6 \mathrm{MV}$ photon beams (TrueBeam ${ }^{\circledR}$,
Varian Medical Systems). Gold fiducial markers were allowed but were not mandatory, IGRT with cone beam CT scan before each treatment fraction was mandatory to verify the consistency of rectal and bladder configuration.

Study endpoints. The primary endpoint of the present study was biochemical disease-free survival (bDFS), defined by Phoenix criteria as PSA nadir after SRT $+2 \mathrm{ng} / \mathrm{ml}$. All biochemical failures were confirmed with a second PSA reading at month 1 of followup. For the first 24 months after SRT, definition of a PSA failure required three consecutive rises in PSA, since a benign PSA bounce is seen in up to $20 \%$ of patients usually within the first 2 years after SBRT (8). PSA was assessed at 90 days after SRT, 180 days and every 6 months until year 10 of follow-up.

The secondary endpoints were overall survival (OS), defined from the last day of SRT to last follow-up or death (any cause); acute toxicity, defined as any adverse event probably or possibly related to treatment that occurred during or within 6 months after SRT; late toxicity, defined as any adverse event probably or possibly related to treatment that occurred after 6 months of SRT, both scored according to the Common terminology criteria for adverse events (CTCAE) version 5.0 (16); patient-reported outcomes, evaluated using internationally validated questionnaires such as International Prostate symptoms score (IPSS) and international erectile function score (IEEF) administered before SRT, the last day of treatment, at 90 days, 180 days and every 6 months until year 10 of follow-up.

Statistical analysis. Univariate analysis was performed to identify variables with a statistically significant impact on primary and secondary survival endopoints. Survival analysis was performed using the Kaplan-Meier method and the log rank test was applied to compare the effect of the individual variables on the different outcomes (a $p$-value $<0.05$ was considered significant). The variables analyzed in the univariate model were as follows: age, NCCN risk classification, Gleason score, initial PSA, tumor node metastasis (TNM) stage, presence of diabetes, hypertension and anti-coagulant or anti-clumping drug therapy, ADT therapy, type of ADT (LHRH agonist, LHRH antagonist, antiandrogen drug), ADT lasting (less or more than 6 months) and PSA bounce. Variables that resulted statistically significant at univariate analysis were included in the multivariate Cox regression model to confirm their independent impact on the outcome. Moreover, toxicity and international index of erectile function (IIEF) in patients treated with SRT alone or SRT plus ADT were analyzed with chi-square test. All the statistical analyses were done using IBM $^{\circledR}$ SPSS $^{\circledR}$ v.23.0 software (SPSS, Chicago, IL, USA).

\section{Results}

Patient characteristics. We identified 170 consecutive patients meeting the inclusion criteria. Patient characteristics are summarized in Table I. Median age was 75 years old (range $=56-82), 49$ patients $(28.8 \%)$ belonged to low-risk category, $15(8.8 \%)$ to favorable intermediate-risk, 76 $(44.7 \%)$ to unfavorable intermediate-risk and 30 patients (17.6\%) to high-risk class. ADT was administered to all patients of unfavorable intermediate- and high-risk groups $(n=106,62 \%)$. 
Table I. Clinicopathological characteristics of the patients.

\begin{tabular}{|c|c|}
\hline Characteristic & $\mathrm{n}(\%)$ \\
\hline \multicolumn{2}{|l|}{ Age } \\
\hline$<75$ & $73(42.9)$ \\
\hline$\geq 75$ & $97(57.1)$ \\
\hline \multicolumn{2}{|l|}{ Diabetes } \\
\hline No & $147(86.5)$ \\
\hline Yes & $23(13.5)$ \\
\hline \multicolumn{2}{|l|}{ Hypertension } \\
\hline No & $78(45.9)$ \\
\hline Yes & $92(54.1)$ \\
\hline \multicolumn{2}{|c|}{ Anticoagulant/anti-clumping drug } \\
\hline No & $106(62.4)$ \\
\hline Yes & $64(37.6)$ \\
\hline \multicolumn{2}{|l|}{ PSA at diagnosis } \\
\hline$<10 \mathrm{ng} / \mathrm{ml}$ & $114(67.1)$ \\
\hline $10-20 \mathrm{ng} / \mathrm{ml}$ & $43(25.3)$ \\
\hline$>20 \mathrm{ng} / \mathrm{ml}$ & $17(7.6)$ \\
\hline \multicolumn{2}{|l|}{ T stage (TNM VIII) } \\
\hline $\mathrm{T} 1 \mathrm{c}$ & $96(56.5)$ \\
\hline $\mathrm{T} 2 \mathrm{a}-\mathrm{b}$ & $60(35.3)$ \\
\hline $\mathrm{T} 2 \mathrm{c}$ & $4(2.4)$ \\
\hline T3a-b/T4 & $10(5.9)$ \\
\hline \multicolumn{2}{|l|}{ ISUP grade } \\
\hline 1 & $66(38.8)$ \\
\hline 2 & $61(35.8)$ \\
\hline 3 & $21(12.4)$ \\
\hline 4 & $11(6.5)$ \\
\hline 5 & $11(6.5)$ \\
\hline \multicolumn{2}{|l|}{ N'Amico/NCCN risk class } \\
\hline Low & $49(28)$ \\
\hline Intermediate favorable & $15(8)$ \\
\hline Intermediate unfavorable & $76(44.7)$ \\
\hline High & $30(17.6)$ \\
\hline \multicolumn{2}{|l|}{ ADT } \\
\hline No & $64(38)$ \\
\hline Yes & $106(62)$ \\
\hline \multicolumn{2}{|l|}{ ADT lasting } \\
\hline 6 months & $53(50)$ \\
\hline 24-36 months & $53(50)$ \\
\hline
\end{tabular}

PSA: Prostate-specific antigen; ISUP: International Society of Urological Pathology; NCCN: National Comprehensive Cancer Network; ADT: androgen deprivation therapy.

Biochemical DFS and OS. After a median follow-up of 41 months (range $=31-61$ ), median bDFS was not reached and 5 -year bDFS was $88 \%$. At univariate analysis, factors associated with worse bDFS included intermediate unfavorable and high-risk class, PSA $>20 \mathrm{ng} / \mathrm{ml}$, ISUP 3 to 5 and $\mathrm{T}$ stage. Patients with unfavorable intermediate- and high- risk presented a 5-year bDFS of $81.7 \%$ and $76.9 \%$, respectively, while favorable intermediate- and low- risk patients presented a 5-year bDFS of $100 \%$ and $93 \%$, respectively. Median OS was not reached and 5-year OS was $83.2 \%$. On univariate analysis, primary tumor stage T3a-b or T4 was the only variable significantly associated with worse
OS $(p=0.001)$. Univariate analysis results concerning bDFS and OS are summarized in Table II. Multivariate analysis showed only ISUP 4 or 5 to be associated with a worse bDFS [relative risk $(\mathrm{RR})=16,95 \%$ confidence interval $(\mathrm{CI})=3.2-90, p=0.001]$.

Acute and late toxicity. Concerning maximum acute genitourinary (GU) and gastrointestinal (GI) toxicity, in the first evaluation performed during and at the end of SRT, 47 patients $(27.6 \%)$ experienced grade G2 urinary simptoms, 2 patients $(1.2 \%)$ experienced G2 acute proctitis. During the first 6 months after SRT, maximum toxicity was represented by 1 case $(0.6 \%)$ of G3 urinary stricture that necessitated urgent management with TURP. Regarding late maximum toxicity, one year after SRT, 1 patient $(0.6 \%)$ experienced a G3 cystitis that required hospitalization; no GI toxicity more than G1 was registered until the end of follow-up.

More specifically, in the patient groups treated with SRT plus $\mathrm{AD}$, acute GU toxicity was reported in 24 patients (G2 toxicity in 23 and $1 \mathrm{G} 3$ urinary stricture in 1 patient), while no cases of acute GI toxicity were registered. In addition, no cases of G2 late GU/GI toxicity were registered in SRT+ADT groups.

As it was expected, no statistically significant difference was observed between patients treated with SRT alone and SRT plus ADT in terms of maximum GU and GI toxicities. Moreover, ADT was not discontinued in any patient due to toxicity. Timing and grade of GU and GI toxicity for the whole series of patients is presented in Figure 1.

Patient-reported outcomes. IPSS was assessed for the whole series of patients until one year of follow-up. The mean basal value was 5.1 (range=0-17), while on the last day of SRT IPSS resulted 6.7 (range $=0-20)$. After 3 and 6 months, mean IPSS was 5.2 (range=0-17) and $5.4 \quad($ range=1-25), respectively. At 1 year, it resulted 4.9 (range=1-16). Thereafter the mean score was maintained 5 or lower, while the maximum value did not reach more than 15. Evolution of IPSS score before, during and after SRT is reported in Figure 2 .

IIEF was also assessed for the whole series until one year of follow-up. The mean basal value was 3.7 (range=0-23), while the majority of patients $(140,82 \%)$ had zero score zero. On the last day of SRT, mean IIEF was 2.8 (range=020). After 3 and 6 months, mean IIEF resulted 4.5 (range $=0$ 20 ) and 3.3 (range $=0-20$ ), respectively. At 1 year, it resulted 2.9 (range $=0-20$ ) and at 3 years, the mean score reached 6 (range=0-20). Evolution of IPSS before, during and after SRT is reported in Figure 3.

Moreover, we performed a subgroup analysis of IIEF in patients treated with SRT alone or SRT plus ADT. Mean basal IIEF resulted 0 for both subgroups, with a range between 0-23 for the SRT plus ADT group and 0-20 for the 
in vivo $36: 306-313$ (2022)

Table II. Univariate analysis for biochemical disease-free survival (bDFS) and overall survival (OS).

\begin{tabular}{|c|c|c|c|c|c|c|c|c|}
\hline \multirow[b]{2}{*}{ Predictor } & \multicolumn{4}{|c|}{ bDFS } & \multicolumn{4}{|c|}{ OS } \\
\hline & Median (months) & 3-year & 5 -year & $p$-Value & Median (months) & 3-year & 5 -year & $p$-Value \\
\hline Total population & Not reached & $93 \%$ & $88 \%$ & & Not reached & $93 \%$ & $83.2 \%$ & \\
\hline \multicolumn{9}{|l|}{ Age } \\
\hline$<75$ & Not reached & $93 \%$ & $88.1 \%$ & Reference & Not reached & $94.4 \%$ & $77.7 \%$ & Reference \\
\hline$\geq 75$ & Not reached & $93 \%$ & $83.4 \%$ & NS & Not reached & $92.2 \%$ & $92.2 \%$ & NS \\
\hline \multicolumn{9}{|l|}{ PSA at diagnosis } \\
\hline$<10 \mathrm{ng} / \mathrm{ml}$ & Not reached & $97 \%$ & $91 \%$ & Reference & Not reached & $95 \%$ & $87.7 \%$ & Reference \\
\hline $10-20 \mathrm{ng} / \mathrm{ml}$ & Not reached & $88 \%$ & $88 \%$ & NS & Not reached & $86.9 \%$ & $77.2 \%$ & NS \\
\hline $\begin{array}{l}>20 \mathrm{ng} / \mathrm{ml} \\
\mathrm{T} \text { stage (TNM VIII) }\end{array}$ & Not reached & $70.7 \%$ & $70.7 \%$ & 0.014 & 42 & $87.5 \%$ & $43.8 \%$ & NS \\
\hline $\mathrm{T} 1 \mathrm{c}$ & Not reached & $96 \%$ & $89.8 \%$ & Reference & Not reached & $94.7 \%$ & $83.4 \%$ & Reference \\
\hline $\mathrm{T} 2 \mathrm{a}-\mathrm{b}$ & Not reached & $91.2 \%$ & $91.2 \%$ & NS & Not reached & $94.3 \%$ & $86.1 \%$ & NS \\
\hline $\mathrm{T} 2 \mathrm{c}$ & Not reached & $100 \%$ & $100 \%$ & NS & Not reached & $100 \%$ & $100 \%$ & NS \\
\hline T3a-b/T4 & Not reached & $70 \%$ & $70 \%$ & 0.002 & Not reached & $64 \%$ & $64 \%$ & 0.001 \\
\hline \multicolumn{9}{|l|}{ ISUP grade } \\
\hline 1 & Not reached & $98.4 \%$ & $94.1 \%$ & Reference & Not reached & $96.6 \%$ & $89.0 \%$ & Reference \\
\hline 2 & Not reached & $89.2 \%$ & $84 \%$ & NS & Not reached & $93 \%$ & $83.3 \%$ & NS \\
\hline 3 & 55 & $100 \%$ & $0 \%$ & 0.003 & 46.5 & $80 \%$ & $40 \%$ & NS \\
\hline 4 & Not reached & $90 \%$ & $90 \%$ & NS & Not reached & $75 \%$ & $75 \%$ & NS \\
\hline 5 & Not reached & $65 \%$ & $65 \%$ & 0.04 & Not reached & $83 \%$ & $83 \%$ & NS \\
\hline \multicolumn{9}{|l|}{$\begin{array}{l}\mathrm{D}^{\prime} \text { Amico/NCCN } \\
\text { risk class }\end{array}$} \\
\hline Low & Not reached & $98 \%$ & $92.8 \%$ & Reference & Not reached & $100 \%$ & $88.6 \%$ & Reference \\
\hline $\begin{array}{l}\text { Intermediate } \\
\text { favorable }\end{array}$ & Not reached & $100 \%$ & $100 \%$ & NS & Not reached & $80 \%$ & $80 \%$ & NS \\
\hline $\begin{array}{l}\text { Intermediate } \\
\text { unfavorable }\end{array}$ & Not reached & $92.7 \%$ & $81.7 \%$ & 0.02 & Not reached & $91.8 \%$ & $81.8 \%$ & NS \\
\hline High & Not reached & $79.6 \%$ & $79.6 \%$ & 0.02 & Not reached & $90.5 \%$ & $67.9 \%$ & NS \\
\hline \multicolumn{9}{|l|}{ ADT } \\
\hline No & Not reached & $97.1 \%$ & $93.6 \%$ & Reference & Not reached & $98.8 \%$ & $95 \%$ & Reference \\
\hline Yes & Not reached & $88.2 \%$ & $81.4 \%$ & NS & Not reached & $86.2 \%$ & $67.4 \%$ & NS \\
\hline \multicolumn{9}{|l|}{ ADT duration } \\
\hline 6 months & Not reached & $94.7 \%$ & $94.7 \%$ & Reference & Not reached & $92.4 \%$ & $71.9 \%$ & Reference \\
\hline 24 months & Not reached & $82 \%$ & $74 \%$ & NS & Not reached & $80.5 \%$ & $63.4 \%$ & NS \\
\hline
\end{tabular}

PSA: Prostate-specific antigen; ISUP: International Society of Urological Pathology; NCCN: National Comprehensive Cancer Network; ADT: androgen deprivation therapy; NS: not significant.

SRT alone group. Thereafter, mean IIEF remained at zero in both groups at follow-up. Chi-square test was subsequently perfomed and showed no significant difference of IIEF between the two patient groups.

\section{Discussion}

The dramatic technological evolution in radiation oncology led to increased availability of SRT, a relatively new treatment option that allows performing safe dose-escalation. It has been shown that SRT is not inferior to traditional fractionation and moreover, it requires relatively low number of fractions. The randomized PACE B trial results confirmed that ultra-hypofractionated prostate irradiation presents a similar safety profile compared to standard radiotherapy, while Hypo-RT-PC trial showed that SRT is not inferior to normofractionated radiotherapy alone. Remarkably, several recent studies, including clinical trials, have tested SRT efficacy on localized prostate cancer omitting ADT (6-8, 1114, 17).

Of note, ADT is widely recognized to improve outcomes in combination with standard and moderate fractionated radiotherapy for a subclass of intermediate risk and high-risk prostate cancer patients. Biological rationale of combining RT and ADT were reported in literature (18), although the role of ADT in the context of high dose-per-fraction schedule is still uncertain (19). Based on the results of CHHiIPP and HYPRO trials, moderate hypofractionated RT regimens and short term ADT are considered not inferior to standard fractionation plus ADT (3-5). 


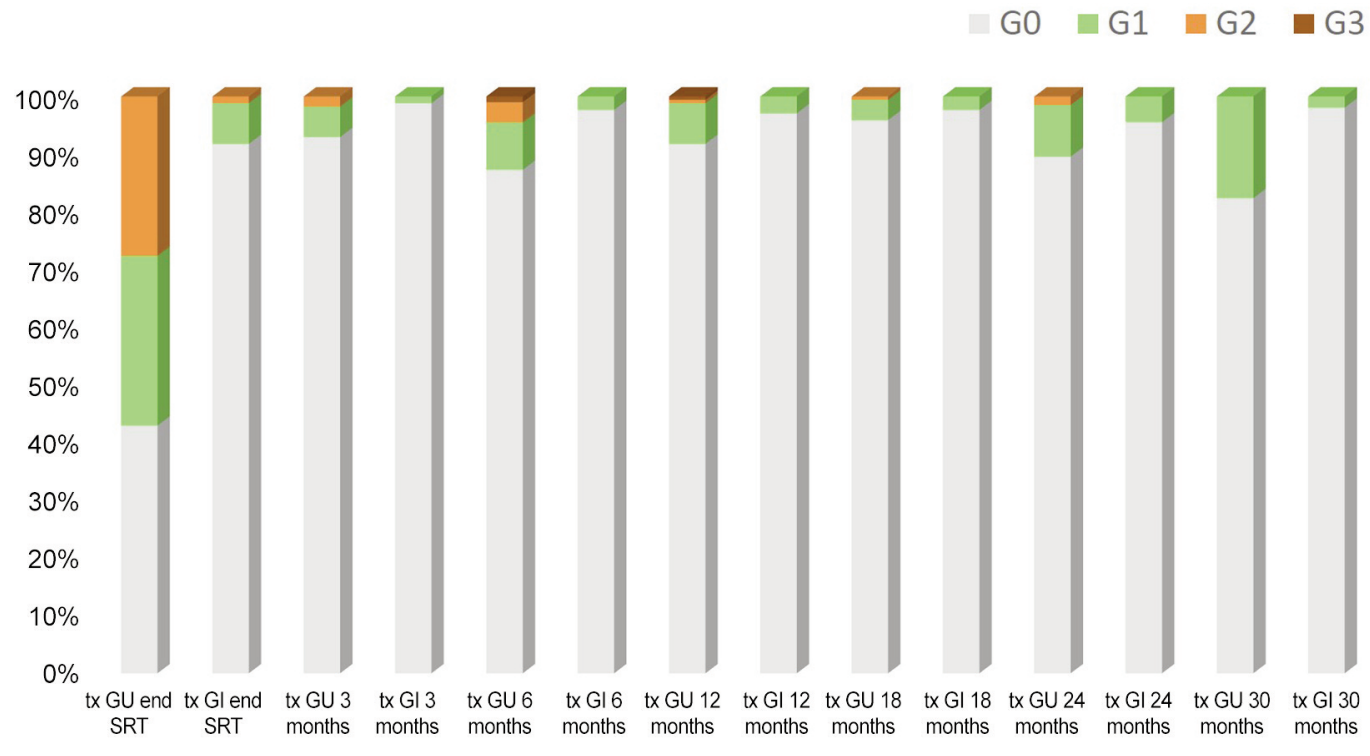

Figure 1. Timeline for genito-unirary (GU) and gastro-intestinal (GI) toxicities (tox).

In the Hypo-RT-PC trial, prostate cancer patients were randomized to standard RT versus SRT, and ADT was omitted for intermediate unfavourable- and high- risk patients in both groups. However, recent studies have shown that intermediate risk prostate cancer is an heterogeneous class, in which unfavorable intermediate-risk disease may present an aggressive biological behavour, thus being more related the high-risk group than the intermediate one (14). Therefore, in our view, the role of ADT in such context needs to be better clarified.

In the present study, bDFS and toxicity results confirmed SRT as a safe and effective treatment for localized prostate cancer also in the context of intermediate unfavorable- and high- risk patients. SRT delivery with V-MAT thechnique ensures inter-fraction reproducibility of rectal and bladder set-up, owing to cone beam CT and fast delivery, without urinary catheterization. Clinician-reported acute toxicity outcomes reached a maximum score at the end of SRT, while late toxicity profile was mild with only two cases of G3 urinary late toxicity. No G3 or more acute and late GI toxicity was recorded. PROs showed an increase in IPSS score during and immediately after SRT, a decrease at 6 months and stabilization of the score thereafter. IIEF score was stable from the last day of SRT until 1 year of followup, despite the majority of patients presented a score indicating severe dysfunction even before treatment.

In literature, only a minority of prostate cancer patients have been trated with SRT plus ADT. Therefore, there is scarce evidence on the impact of combination therapy to these patients. Moreover, ADT prescription is rarely administered per-protocol but only at "investigator's choice" and this aspect could limit the quality of the evidence that could be extracted. However, there are some studies that have investigated the afficacy of prostate SRT plus ADT.

Katz and colleagues have reported the results of prostate SRT for 515 patients, demonstrating a 7-year bDFS of $93.6 \%, 84.3 \%$ and $65 \%$ for low, intermediate and high-risk group, respectively. ADT was used in $14 \%$ of patients, and did not have any impact on bDFS. Importantly, they found a 7 -year bDFS of $68.2 \%$ for the unfavorable intermediate- risk class. The authors underlined that unfavorable intermediaterisk patients presented similar outcomes to the high-risk ones and concluded that in this category of patients, efforts must be made in order to find systemic strategies to optimize treatment outcomes (14).

A pooled analysis by King et al. including 1,100 patients treated with SRT for localized prostate cancer in prospective trials, reported no bDFS advantage in ADT group (12). It must be underlined that ADT was prescribed at clinical judgment without a risk-adapted strategy; in fact, only $15 \%$ and $38 \%$ of patients in intermediate- and high-risk group, respectively, received ADT. Moreover, this study clearly showed the tendency of current literature not to report specific outcomes for favorable and unfavorable intermediate-risk disease categories.

A recent meta-analysis by Jackson et al. that included over 6,000 patients treated with prostate SRT in prospective studies showed that $15 \%$ of patients received ADT and no advantage in bDFS was observed. Interestingly, authors concluded that there was neither enough information available to determine the impact of ADT in a quantitative manner, nor the ADT duration was always specified (6). 
IPSS

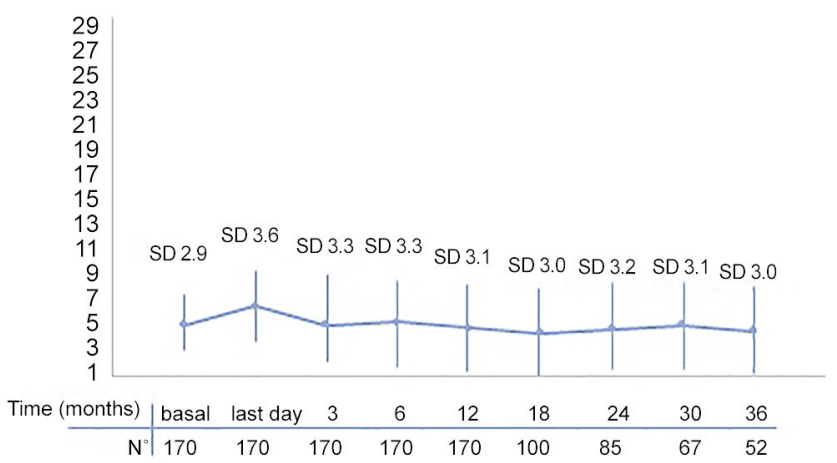

Figure 2. Timeline for International prostate syntoms scale (IPSS), before, last day and after stereotactic radiotherapy (SRT).

Moreover, in this study, there are many restrictions that limit interpretation of SRT-ADT effect. For example, there is a frequent ADT administration in low risk class and omission for the majority of intermediate- and high-risk patients that theroretically are the two subclasses were ADT could be of benefit. Taken toghether, the aforementioned studies clearly highlight that quality of data about ADT -SRT for localized prostate cancer need to be improved.

A comparison of our bDFS results with studies that do not use systematically ADT is difficult. HYPO-RT-PC trial presented a low prevalence of high-risk subclass, limiting conclusions about bDFS, and did not report separate outcomes for the unfavorable intermediate-risk class (7). Also the study by Jackson et al. did not provide bDFS per disease class (6). Moreover, the study conducted by Katz and colleagues showed disappointing results in terms of bDFS in high-risk and unfavourable intermediate-risk groups; however, bDFS outcome was computed at 7 years (14). Nevertheless, it is important to underline that unfavorable intermediate- and high- risk patients in our series presented relatively fair outcomes, with a 5 -year bDFS of $81.7 \%$ and $79.6 \%$, respectively. Given the favorable result obtained, we hypothesize that an effect given by the combination with ADT cannot be excluded. Favorable intermediate-risk patients presented a 5-year bDFS of $93 \%$, probably reflecting a less aggressive biology. Thus, our results support the need for a deeper comprehension of ADT effect in combination with ultra-hypofractionated radiotherapy.

The strength of our study is the homogeneity concerning ADT prescription by prostate cancer risk class, dose prescriptions, radiotherapy planning, delivery and a strict follow-up protocol with a particular attention for PROs. To the best of our knowledge, our study is the first to report results of patients treated per-protocol with SRT plus ADT for unfavorable intermediate- and high- risk prostate cancer.

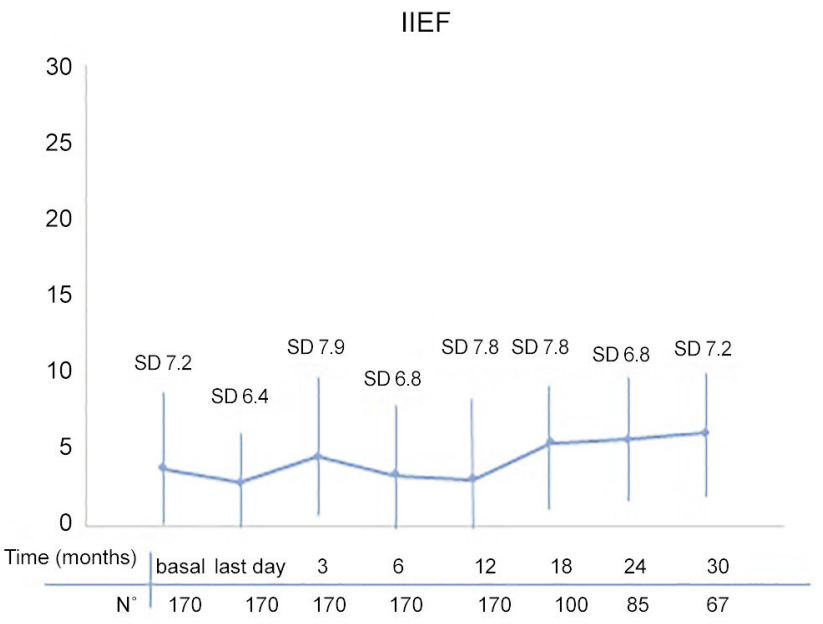

Figure 3. Timeline for international index of erectile function (IIEF) before, last day and after stereotactic radiotherapy (SRT).

Moreover, it is one of the few to report specific outcomes for favorable and unfavorable intermediate-risk disease, which has been used ab initio to select patients for SRT plus ADT strategy. A potential weakness of the present study consists in its retrospective nature. Moreover, given that all of the unfavorable intermediate- and high- risk patients were treated with SRT and ADT, it is impossible to extrapolate any potential difference in patient outcomes between those treated with SRT plus ADT or SRT alone. Another limitation could be identified in the relatively short follow-up.

\section{Conclusion}

SRT consisting of $42 \mathrm{~Gy}$ in seven fractions with short-term ADT represents a safe and effective treatment for unfavorable intermediate- and high- risk prostate cancer. Evidence on the efficacy of STR plus ADT is scarce, as a consequence, specific practice guidelines for the administration of SRT-ADT in prostate cancer are missing, with the concrete risk of ADT omission. Our results support that it is necessary to clarify the role of SRT plus ADT in a prospective and randomized fashion, to demonstrate whether a benefit in bDFS exists also in the context of ultrahypofractionated radiotherapy.

\section{Conflicts of Interest}

The Authors declare no conflicts of interest.

\section{Authors' Contributions}

Alessandro Magli designed the study, enrolled patients planned and delivered SRT for the whole series. Moreover conducted follow- 
up. Marco Lorenzo Bonú participated in study design, data management and analysis, writing and completing manuscript. Fabrizio Tonetto enrolled patients, planned and delivered SRT, revised manuscript Eugenia Moretti enrolled patients, planned and delivered SRT revised manuscript Gioacchino De Giorgi enrolled patients, placed fiducial markers, revised manuscript. Luigi Spiazzi participated in study design, data management and analysis, revising and completing manuscript. Davide Tomasini participated in study design, data analysis, revising and completing manuscript. Marco Trovò enrolled patients, planned and delivered SRT for the whole series, and revised manuscript. Stefano Maria Magrini participated in study design, data management and analysis, revising and completing manuscript. Luca Triggiani important role in study design, data management and analysis, writing and completing manuscript.

\section{References}

1 Hamdy FC, Donovan JL, Lane JA, Mason M, Metcalfe C, Holding P, Davis M, Peters TJ, Turner EL, Martin RM, Oxley J, Robinson M, Staffurth J, Walsh E, Bollina P, Catto J, Doble A, Doherty A, Gillatt D, Kockelbergh R, Kynaston H, Paul A, Powell P, Prescott S, Rosario DJ, Rowe E, Neal DE and ProtecT Study Group: 10-year outcomes after monitoring, surgery, or radiotherapy for localized prostate cancer. N Engl J Med 375(15): 1415-1424, 2016. PMID: 27626136. DOI: 10.1056/ NEJMoa 1606220

2 Dasu A and Toma-Dasu I: Prostate alpha/beta revisited - an analysis of clinical results from 14168 patients. Acta Oncol 51(8): 963-974, 2012. PMID: 22966812. DOI: 10.3109/ 0284186X.2012.719635

3 Dearnaley D, Syndikus I, Mossop H, Khoo V, Birtle A, Bloomfield D, Graham J, Kirkbride P, Logue J, Malik Z, Money-Kyrle J, O'Sullivan JM, Panades M, Parker C, Patterson H, Scrase C, Staffurth J, Stockdale A, Tremlett J, Bidmead M, Mayles H, Naismith O, South C, Gao A, Cruickshank C, Hassan S, Pugh J, Griffin C, Hall E and CHHiP Investigators: Conventional versus hypofractionated high-dose intensitymodulated radiotherapy for prostate cancer: 5-year outcomes of the randomised, non-inferiority, phase $3 \mathrm{CHHiP}$ trial. Lancet Oncol 17(8): 1047-1060, 2016. PMID: 27339115. DOI: 10.1016/ S1470-2045(16)30102-4

4 Lee WR, Dignam JJ, Amin MB, Bruner DW, Low D, Swanson GP, Shah AB, D’Souza DP, Michalski JM, Dayes IS, Seaward SA, Hall WA, Nguyen PL, Pisansky TM, Faria SL, Chen Y, Koontz BF, Paulus R and Sandler HM: Randomized Phase III noninferiority study comparing two radiotherapy fractionation schedules in patients with low-risk prostate cancer. J Clin Oncol 34(20): 2325-2332, 2016. PMID: 27044935. DOI: 10.1200/ JCO .2016 .67 .0448

5 Catton CN, Lukka H, Gu CS, Martin JM, Supiot S, Chung PWM, Bauman GS, Bahary JP, Ahmed S, Cheung P, Tai KH, Wu JS, Parliament MB, Tsakiridis T, Corbett TB, Tang C, Dayes IS, Warde P, Craig TK, Julian JA and Levine MN: Randomized trial of a hypofractionated radiation regimen for the treatment of localized prostate cancer. J Clin Oncol 35(17): 1884-1890, 2017. PMID: 28296582. DOI: 10.1200/JCO.2016.71.7397

6 Jackson WC, Silva J, Hartman HE, Dess RT, Kishan AU, Beeler WH, Gharzai LA, Jaworski EM, Mehra R, Hearn JWD, Morgan TM, Salami SS, Cooperberg MR, Mahal BA, Soni PD,
Kaffenberger S, Nguyen PL, Desai N, Feng FY, Zumsteg ZS and Spratt DE: Stereotactic body radiation therapy for localized prostate cancer: a systematic review and meta-analysis of over 6,000 patients treated on prospective studies. Int J Radiat Oncol Biol Phys 104(4): 778-789, 2019. PMID: 30959121. DOI: 10.1016/j.jirobp.2019.03.051

7 Widmark A, Gunnlaugsson A, Beckman L, Thellenberg-Karlsson C, Hoyer M, Lagerlund M, Kindblom J, Ginman C, Johansson B, Björnlinger K, Seke M, Agrup M, Fransson P, Tavelin B, Norman D, Zackrisson B, Anderson H, Kjellén E, Franzén L and Nilsson P: Ultra-hypofractionated versus conventionally fractionated radiotherapy for prostate cancer: 5-year outcomes of the HYPO-RT-PC randomised, non-inferiority, phase 3 trial. Lancet 394(10196): 385-395, 2019. PMID: 31227373. DOI: 10.1016/S0140-6736(19)31131-6

8 Brand DH, Tree AC, Ostler P, van der Voet H, Loblaw A, Chu W, Ford D, Tolan S, Jain S, Martin A, Staffurth J, Camilleri P, Kancherla K, Frew J, Chan A, Dayes IS, Henderson D, Brown S, Cruickshank C, Burnett S, Duffton A, Griffin C, Hinder V, Morrison K, Naismith O, Hall E, van As N and PACE Trial Investigators: Intensity-modulated fractionated radiotherapy versus stereotactic body radiotherapy for prostate cancer (PACEB): acute toxicity findings from an international, randomised, open-label, phase 3, non-inferiority trial. Lancet Oncol 20(11): 1531-1543, 2019. PMID: 31540791. DOI: 10.1016/S14702045(19)30569-8

9 National Comprehensive Cancer Network. NCCN Clinical Practice Guidelines in Oncology: Prostate Cancer Version 1.2021. Available at: https://www.nccn.org/professionals/ physician_gls/pdf/prostate.pdf [Last accessed on November 15, 2021]

10 Bolla M, Maingon P, Carrie C, Villa S, Kitsios P, Poortmans PM, Sundar S, van der Steen-Banasik EM, Armstrong J, Bosset JF, Herrera FG, Pieters B, Slot A, Bahl A, Ben-Yosef R, Boehmer D, Scrase C, Renard L, Shash E, Coens C, van den Bergh AC and Collette L: Short androgen suppression and radiation dose escalation for intermediate- and high-risk localized prostate cancer: results of EORTC trial 22991. J Clin Oncol 34(15): 1748-1756, 2016. PMID: 26976418. DOI: 10.1200/JCO. 2015.64.8055

11 Park Y, Park HJ, Jang WI, Jeong BK, Kim HJ and Chang AR: Long-term results and PSA kinetics after robotic SBRT for prostate cancer: multicenter retrospective study in Korea (Korean radiation oncology group study 15-01). Radiat Oncol 13(1): 230, 2018. PMID: 30470253. DOI: 10.1186/s13014-018$1182-\mathrm{z}$

12 King CR, Freeman D, Kaplan I, Fuller D, Bolzicco G, Collins S, Meier R, Wang J, Kupelian P, Steinberg M and Katz A: Stereotactic body radiotherapy for localized prostate cancer: pooled analysis from a multi-institutional consortium of prospective phase II trials. Radiother Oncol 109(2): 217-221, 2013. PMID: 24060175. DOI: 10.1016/j.radonc.2013.08.030

13 Miszczyk L, Namysł-Kaletka A, Napieralska A, Kraszkiewicz M, Miszczyk M, Woźniak G, Stąpór-Fudzińska M, Głowacki G and Tukiendorf A: Stereotactic ablative radiotherapy for prostate cancer-the treatment results of 500 patients and analysis of failures. Technol Cancer Res Treat 18: 1533033819870815, 2019. PMID: 31462169 . DOI: $10.1177 / 1533033819870815$

14 Katz A, Formenti SC and Kang J: Predicting biochemical disease-free survival after prostate stereotactic body 
radiotherapy: Risk-stratification and patterns of failure. Front Oncol 6: 168, 2016. PMID: 27458572. DOI: 10.3389/fonc. 2016.00168

15 Prescribing, recording, and reporting photon-beam intensitymodulated radiation therapy (IMRT): Contents. J ICRU 10: 1106, 2010. DOI: $10.1093 /$ jicru/ndq002

16 Common Terminology Criteria for Adverse Events (CTCAE) v5.0. Available at: https://ctep.cancer.gov/protocoldevelopment/ electronic_applications/ctc.htm [Last accessed on November 15, 2021]

17 Cuccia F, Corradini S, Mazzola R, Spiazzi L, Rigo M, Bonù ML, Ruggieri R, Buglione di Monale E Bastia M, Magrini SM and Alongi F: MR-guided hypofractionated radiotherapy: Current emerging data and promising perspectives for localized prostate cancer. Cancers (Basel) 13(8): 1791, 2021. PMID: 33918650. DOI: 10.3390/cancers 13081791
18 Zietman AL: The case for neoadjuvant androgen suppression before radiation therapy. Mol Urol 4(3): 203-8; discussion 215, 2000. PMID: 11062375.

19 Vargas C, Martínez A, Galalae R, Demanes J, Harsolia A, Schour L, Nuernberg $\mathrm{N}$ and Gonzalez J: High-dose radiation employing external beam radiotherapy and high-dose rate brachytherapy with and without neoadjuvant androgen deprivation for prostate cancer patients with intermediate- and high-risk features. Prostate Cancer Prostatic Dis 9(3): 245-253, 2006. PMID: 16786040. DOI: 10.1038/sj.pcan.4500882

Received July 20, 2021

Revised November 5, 2021

Accepted November 15, 2021 